[0212-7199 (2005) 22: 6; pp 279-282] ANALES DE MEDICINA INTERNA Copyright (@) 2005 ARAN EDICIONES, S.L.

AN. MED INTERNA (Madrid) Vol. 22, N. ${ }^{\circ} 6$, pp. 279-282, 2005

\title{
Meningitis y absceso cerebral por Streptococcus intermedius en un paciente con infección por VIH-1
}

\author{
M. VALLALTA MORALES, E. SOLAZ MORENO, J. LACRUZ RODRIGO', \\ M. SALAVERT LLETÍ ${ }^{1}$, G. SILLA BURDALO, C. PÉREZ-BELLÉS ${ }^{2}$
}

Servicio de Medicina Interna. ${ }^{1}$ Unidad de Enfermedades Infecciosas. ${ }^{2}$ Servicio de Microbiología. Hospital Universitario La Fe. Valencia

MENINGITIS AND BRAIN ABSCESS CAUSED BY STREPTOCOCCUS INTERMEDIUS IN A PATIENT INFECTED WITH HIV- 1

\section{RESUMEN}

Los estreptococos de grupo milleri se caracterizan por su tendencia a provocar infecciones piógenas invasoras en diferentes localizaciones. Las meningitis estreptocócicas no neumocócicas son poco frecuentes en pacientes adultos y pueden asociarse a la presencia de un absceso cerebral. Los abscesos cerebrales son colecciones localizadas dentro del parénquima cerebral que se originan como complicación de una infección, siendo los estreptococos microaerófilos y las bacterias anaerobias los microorganismos más frecuentemente aislados. Aunque no es inusual la presencia de colecciones intracraneales de etiología infecciosa en pacientes con infección por VIH-1, los abscesos cerebrales producidos por las bacterias piógenas habituales son muy infrecuentes y es $T$. gondii el agente etiológico más frecuente. Aportamos un caso de meningitis y absceso cerebral por $S$. intermedius en un paciente con infección por VIH-1.

PALABRAS CLAVE: Absceso cerebral. Meningitis. Streptococcus grupo milleri. Streptococcus intermedius. Infección HIV. Tratamiento.

\begin{abstract}
Streptococcus milleri group have been recognized as an important pathogens for abscess formation in various organs. Streptococci other than Streptococcus pneumoniae are a rare cause of bacterial meningitis in adults and can be associated with the presence of an undiagnosed brain abscess. Brain abscess is a focal collection within the brain parenchyma wich can arise as a complication of a variety of infections. The most common etiologic organisms in clinical series have been microaerophilic streptococci and anaerobic bacterias. Although intracraneal mass lesions that occur as a result of infection have commonly been reported in patients infected with the human immunodeficiency virus, brain abscess due to the common bacterial pathogens are rarely described in HIV infected patients and Toxoplasma gondii is the organism most frecuently isolated from stereotactic brain biopsy in these patients. We report a patient with both HIV-1 infection and streptococcal meningitis secondary to brain abscess caused by S. intermedius
\end{abstract}

KEY WORDS: Brain abscess. Meningitis. Streptococcus milleri group. Streptococcus intermedius. HIV infections. Therapy.

Vallalta Morales M, Solaz Moreno E, Lacruz Rodrigo J, Salavert Lletí M, Silla Burdalo G, Pérez-Bellés C. Meningitis y absceso cerebral por Streptococcus intermedius en un paciente con infección por VIH-1. An Med Interna (Madrid) 2005; 22: $279-282$.

\section{INTRODUCCIÓN}

Las meningitis estreptocócicas no neumocócicas son poco frecuentes en pacientes adultos (1) y pueden asociarse a la presencia de un absceso cerebral clínicamente oculto hasta en un $24 \%$ de las ocasiones (2). Los abscesos cerebrales son una lesión supurada grave del sistema nervioso central con una mortalidad global del $30 \%$, que llega a superar el $80 \%$ si se produce su ruptura a ventrículos $(3,4)$. Las bacterias más frecuentemente aisladas en ellos son estreptococos microaerófilos y bacterias anaerobias (5). En pacientes infectados por el $\mathrm{VIH}$, los abscesos cerebrales producidos por bacterias pióge- nas convencionales son poco habituales, siendo T. gondii el agente etiológico más frecuente (6). Aportamos un caso de absceso cerebral y meningitis secundaria por Streptococcus intermedius en un paciente con infección por VIH-1.

\section{CASO APORTADO}

Varón de 26 años que consultó por fiebre, cefalea y alteración del nivel de conciencia de 24 horas de evolución. Padecía infección por el VIH- 1 diagnosticada 10 años antes. No había presentado ninguna infección oportunista. La serología para VHB, VHC, lúes y $T$. gondii eran negativas. El paciente seguía tratamiento antirretroviral

Trabajo aceptado: 10 de enero de 2005

Correspondencia: Manuel Vallalta Morales. Avda. Valle de la Ballestera, 40 puerta 33. 46015 Valencia. e-mail: mvallalta@hotmail.com 
de gran actividad y la adherencia era buena. En su último control dos meses antes, tenía unos CD4+ de 303 × 10\% 1 . A la exploración física la temperatura era de $39^{\circ} \mathrm{C}$, la TA $160 / 90 \mathrm{mmHg}$, la frecuencia cardiaca de $100 \mathrm{lpm}$ y la frecuencia respiratoria de $16 \mathrm{rpm}$. La exploración por aparatos era normal. No se palpaban adenopatías. No había candidiasis oral ni boca séptica. No presentaba ningún proceso infeccioso ótico ni odontológico. El fondo de ojo era normal. El paciente estaba somnoliento, confuso y la deambulación era inestable. Presentaba rigidez de nuca y habían signos de irritación meníngea. Los estudios de laboratorio mostraban una leucocitosis de $22.300 \mathrm{cel} / \mathrm{mm}^{3}$ (93\% neutrófilos), sin otras alteraciones significativas. La radiografía de tórax y abdomen fueron normales. En la TAC craneal se observó una lesión focal única en tálamo izquierdo de $1,5 \mathrm{~cm}$ de diámetro con halo hiperintenso y edema asociado, que comprimía III ventrículo produciendo hidrocefalia triventricular (Fig. 1). Se practicó una punción lumbar obteniendo un LCR de aspecto turbio con 164 células $/ \mathrm{mm}^{3}$ (88\% neutrófilos), glucosa de $18 \mathrm{mg} / \mathrm{dl}$ y proteínas de 293 $\mathrm{mg} / \mathrm{dl}$. Ante la existencia de meningitis purulenta y sospecha de absceso cerebral se inició tratamiento con ceftriaxona, metronidazol y ampicilina, además de pirimetamina y sulfadiazina junto a dexametasona. En un nuevo estudio de poblaciones linfocitarias, los CD4+ fueron de $50 \times 10^{6} / 1$.

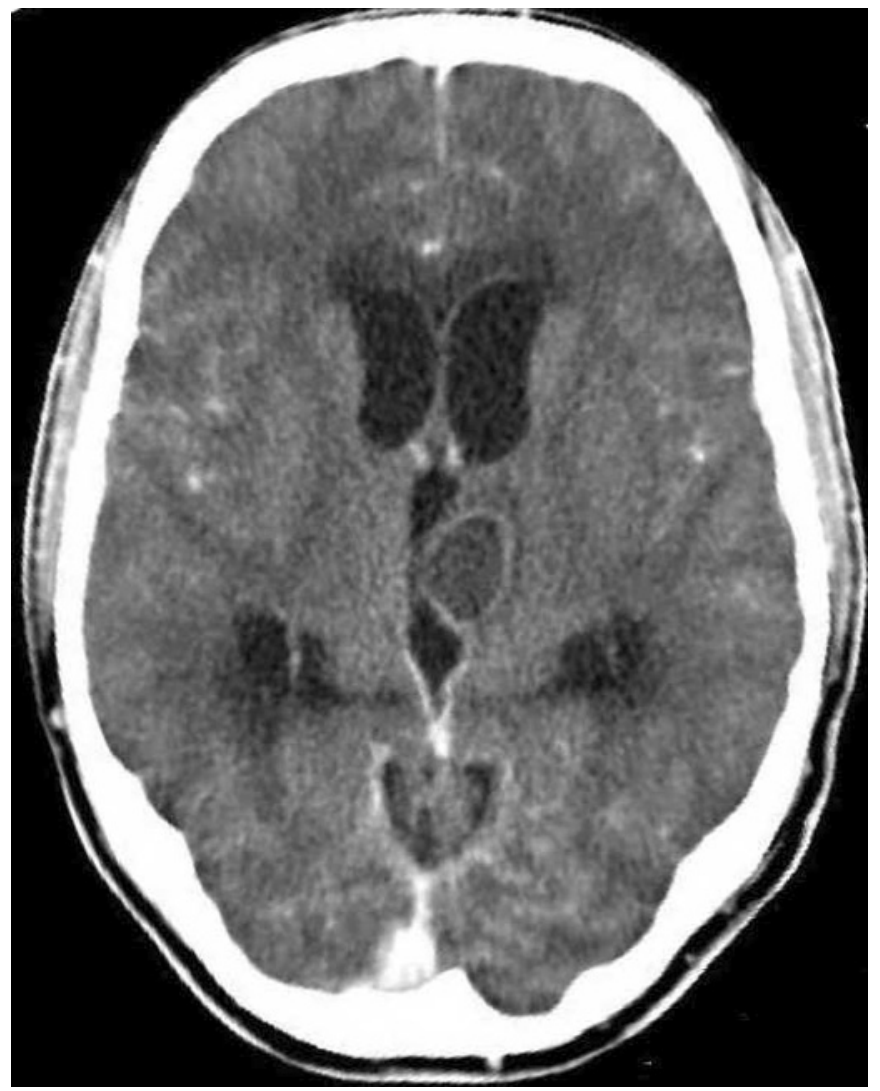

Fig. 1. TAC craneal. Absceso talámico izquierdo con compresión tercer ventrículo y hidrocefalia triventricular.

En la tinción de gram del LCR se observaron escasos cocos gram positivos en forma de diplococos y pequeñas cadenas, no capsulados. El criptolatex, la tinción de Ziehl-Nielsen y la PCR para detección de DNA de $T$. gondii en LCR fueron negativos. Una nueva serología plasmática frente a $T$. gondii fue negativa. No hubo crecimiento en los cultivos especiales para hongos y micobacterias. Los hemocultivos y urinocultivo fueron negativos. A las 48 horas se aisló en los cultivos bacterianos de LCR, un estreptococo identificado como $S$. intermedius sensible a penicilina, clindamicina, eritromicina, levo- floxacino y vancomicina. Se modificó el tratamiento antibiótico a penicilina $\mathrm{G}$ sódica 30 millones de unidades i.v. cada 24 horas, retirándose esteroides y resto de antimicrobianos. La evolución fue favorable, pero al sexto día de ingreso presentó de nuevo fiebre elevada con somnolencia, meningismo e inestabilidad para la marcha. Una nueva TAC cerebral mostró aumento de la talla ventricular y del edema de las astas frontales. Se reintrodujeron esteroides y se añadió clindamicina ( $900 \mathrm{mg} / 8 \mathrm{~h} / \mathrm{i} . \mathrm{v}$.), la cual se mantuvo durante 3 semanas. En las siguientes 24 horas, el paciente quedó afebril y hubo una gran mejoría que se mantuvo durante el resto del ingreso. En posteriores estudios de imagen se observó una progresiva resolución del absceso y de la hidrocefalia, no siendo necesario el drenaje quirúrgico ni la colocación de una derivación ventrículo peritoneal del LCR. El tratamiento antibiótico intravenoso tuvo una duración de 6 semanas y se continuó con 2 semanas más de levofloxacino por vía oral. A los 8 meses, el paciente está asintomático y la RMN de control muestra una completa resolución del absceso cerebral.

\section{DISCUSIÓN}

Streptococcus intermedius forma parte de los estreptococos del grupo milleri junto con $S$. anginosus y $S$. constellatus (7). Aunque se aísla frecuentemente en cavidad oral y nasofaringe donde se le considera un comensal habitual, puede producir infecciones invasoras y piógenas, en diferentes localizaciones entre las que se encuentra el sistema nervioso central (8). Su crecimiento se ve facilitado en las infecciones mixtas polimicrobianas con bacterias anaerobias y por los medios ácidos como el encontrado en los abscesos (9). Su aislamiento en sangre suele asociarse a un proceso supurativo intrabdominal o de otra localización (10) y cuando se aísla en LCR debe hacer sospechar la presencia de un absceso cerebral oculto asociado (2). A diferencia de otras especies de S. viridans, la tasa de resistencia a penicilina continúa siendo baja, inferior al 2\% (11), pudiéndose utilizar clindamicina y vancomicina en casos de alergia a beta-lactámicos. Las nuevas quinolonas (levofloxacino, moxifloxacino) y otros fármacos frente a bacterias gram positivas (linezolid, quinupristina-dalfopristina) también son activos frente a este microorganismo.

Los abscesos cerebrales son a menudo secundarios a un foco supurativo de otra localización que afecta al SNC por contigüidad o diseminación hematógena. S. intermedius, a diferencia de otros S. del grupo viridans, no se asocia a siembra hematógena secundaria a endocarditis bacteriana (2). Tanto la localización del absceso como los microorganismo más frecuentemente aislados, están relacionados con la puerta de entrada de la infección (Tabla I), siendo la localización más frecuente el lóbulo frontal, seguido del parietal y temporal (12). Aunque la realización de una punción lumbar es potencialmente peligrosa y raramente aporta información en el manejo de los pacientes con abscesos cerebrales (3), en nuestro caso, ante la presencia de meningitis asociada, fue de gran utilidad diagnóstica.

La principal complicación de los abscesos cerebrales es la ruptura a ventrículos. Suele presentarse como un aumento súbito de la cefalea, meningismo y alteración del nivel de conciencia. La mortalidad supera el $80 \%$ y se precisa de intervención neuroquirúrgica para conseguir mejorar la supervivencia (4). Aunque al sexto día de tratamiento, nuestro paciente presentó un importante deterioro clínico, una ruptura parcial del absceso al sistema ventricular no se confirmó con las técnicas de imagen. 
TABLA I

ABSCESOS CEREBRALES: LOCALIZACIÓN Y ETIOLOGÍA

\begin{tabular}{|c|c|c|c|}
\hline & Foco & Localización absceso & Microorganismos \\
\hline \multirow{5}{*}{$\begin{array}{l}\mathrm{I} \\
\mathrm{N} \\
\mathrm{M} \\
\mathrm{U} \\
\mathrm{N} \\
\mathrm{O} \\
\mathrm{C} \\
\mathrm{O} \\
\mathrm{M} \\
\mathrm{P} \\
\mathrm{E} \\
\mathrm{T} \\
\mathrm{E} \\
\mathrm{N} \\
\mathrm{T} \\
\mathrm{E}\end{array}$} & Infección sinusal y dental & Lóbulo frontal & $\begin{array}{l}\text { Estreptococos microaerófilos } \\
\text { Haemophilus } \\
\text { Bacterias anaerobias (Bacteroides, } \\
\text { Fusobacterium, estreptococos anae- } \\
\text { robios,...) }\end{array}$ \\
\hline & Infección ótica & Lóbulo temporal y cerebelo & $\begin{array}{l}\text { Streptococcus spp } \\
\text { Bacteroides } \\
\text { Bacilos aerobios gramnegativos }\end{array}$ \\
\hline & $\begin{array}{l}\text { Diseminación hematógena } \\
\text { metastásica }\end{array}$ & $\begin{array}{l}\text { Lesiones cerebrales múltiples, } \\
\text { frecuentemente distribuidas en } \\
\text { territorio arteria cerebral media }\end{array}$ & $\begin{array}{l}\text { Endocarditis } \\
\text { Staphylococcus aureus } \\
\text { Streptococcus viridans } \\
\text { Infecciones urinarias } \\
\text { Enterobacterias } \\
\text { Especies de Pseudomona } \\
\text { Infecciones intraabdominales } \\
\text { Streptococcus spp } \\
\text { Enterobacterias } \\
\text { Bacterias anaerobias } \\
\text { Infecciones pulmonares } \\
\text { Streptococcus spp } \\
\text { Actinomyces } \\
\text { Fusobacterium }\end{array}$ \\
\hline & Traumatismo penetrante & Zona traumatizada & $\begin{array}{l}\text { Staphylococcus aureus } \\
\text { Clostridium } \\
\text { Bacilos aerobios gramnegativos }\end{array}$ \\
\hline & Post-quirúrgico & Zona intervenida & $\begin{array}{l}\text { Staphylococcus epidermidis } \\
\text { Staphylococcus aureus } \\
\text { Bacilos aerobios gramnegativos }\end{array}$ \\
\hline $\begin{array}{l}\mathrm{N} \\
\mathrm{M} \\
\mathrm{U} \\
\mathrm{N} \\
\mathrm{O}\end{array}$ & Enfermo VIH+ & $\begin{array}{l}\text { Diferentes localizaciones y } \\
\text { microorganismos, en función de } \\
\text { situación inmunológica }\end{array}$ & $\begin{array}{l}\text { Toxoplasma gondii* } \\
\text { Bacterias piógenas convencionales } \\
\text { Otros: M. tuberculosis, Nocardia, } \\
\text { Aspergillus, Rhodococcus, Cripto- } \\
\text { coccus,... }\end{array}$ \\
\hline $\begin{array}{l}\mathrm{D} \\
\mathrm{P} \\
\mathrm{R} \\
\mathrm{I}\end{array}$ & $\begin{array}{l}\text { Trasplante órgano sólido- } \\
\text { disfunción inmunidad celular }\end{array}$ & $\begin{array}{l}\text { Diferentes localizaciones y } \\
\text { microorganismos }\end{array}$ & $\begin{array}{l}\text { Toxoplasma gondii } \\
\text { M. tuberculosis, nocardia, listeria,... } \\
\text { Infecciones fúngicas } \\
\text { Bacterias piógenas convencionales }\end{array}$ \\
\hline $\begin{array}{l}\text { M } \\
\text { I } \\
\text { D } \\
\text { O }\end{array}$ & $\begin{array}{l}\text { Enfermo neutropénico/ tras- } \\
\text { plante médula ósea }\end{array}$ & $\begin{array}{l}\text { Diferentes localizaciones y } \\
\text { microorganismos }\end{array}$ & $\begin{array}{l}\text { Infecciones fúngicas: Aspergillus*, } \\
\text { Candida, otras especies } \\
\text { Bacterias aerobias gramnegativas y } \\
\text { piógenas convencionales }\end{array}$ \\
\hline
\end{tabular}

* microorganismos más frecuentes

La etiología más frecuente de las lesiones ocupantes de espacio y abscesos cerebrales en los pacientes con infección por el VIH-1 es infecciosa, aunque debe realizarse diagnóstico diferencial con otras entidades entre las que destacan los procesos neoformativos tanto primarios como metastásicos (13). T. gondii es el microorganismo más frecuentemente detectado a partir de muestras obtenidas de abscesos cerebra- les en estos pacientes (14), pero es infrecuente en aquellos pacientes con CD4+ > 200/ml. Los abscesos cerebrales por bacterias piógenas convencionales son menos frecuentes en estos pacientes. En una revisión de la literatura (MEDLINE 1966-2003), sólo hemos encontrado 6 casos $(6,15-19)$ y ninguno era producido por $S$. intermedius, siendo este, en nuestro conocimiento, el primer caso comunicado. 
Los pacientes infectados por el VIH-1con una lesión cerebral sugestiva de absceso suelen recibir inicialmente de forma empírica tratamiento frente a $T$. gondii, sobretodo si sus CD4+ son inferiores a $200 \mathrm{cel} / \mathrm{ml}$. La asociación de otros antimicrobianos, diferentes al tratamiento frente T.gondii, es adecuada en función de la posibilidad de otras etiologías y de la respuesta inicial al tratamiento antitoxoplasma instaurado. Se aconseja la realización temprana de biopsia cerebral en aquellos pacientes con CD4+> $200 \mathrm{cel} / \mathrm{ml}$ o sin respuesta al tratamiento instaurado (20).

La duración del tratamiento antimicrobiano no está claramente definida y se desconoce si debe ser más prolongada en los pacientes infectados por el VIH, aunque se establece que entre 6 y 8 semanas son suficientes (5). Además de un tratamiento antibiótico eficaz, frecuentemente se precisan técnicas quirúrgicas de drenaje. En los pacientes con alta sospecha de absceso por $T$. gondii se suelen demorar hasta ver la respuesta al tratamiento empírico y en los pacientes con abscesos cerebrales bacterianos menores de $2 \mathrm{~cm}$ pueden no ser necesarias debido a la buena respuesta que se obtiene exclusivamente con tratamiento médico. En nuestro paciente el absceso fue de pequeño tamaño, disponíamos del diagnóstico microbiológico, la evolución era satisfactoria y finalmente no fueron necesarias.

\section{Bibliografía}

1. Durand ML, Calderwood SB, Weber DJ, Miller SI, Southwick FS, Caviness VS, Swartz MN. Acute bacterial meningitis in adults. N Engl J Med 1993; 328: 21-28

2. Cabellos C, Viladrich PF, Corredoira J, Verdaguer R, Ariza J, Gudiol F. Streptococcal meningitis in adult patients: current epidemiology and clinical spectrum. Clin Infect Dis 1999; 28: 1104-1108

3. Mathisen GE, Johnson JP. Brain abscess. Clin Infect Dis 1997; 25: 763 781

4. Zeidman SM, Geisler FH, Olivi A. Intraventricular rupture of a purulent brain abscess: case report. Neurosurgery 1995; 36: 189-193

5. Gortvai P, De Louvois J, Hurley R. The bacteriology and chemotherapy of acute pyogenic brain abscess. Br J Neurosurg 1987; 1: 189-203

6. Maniglia RJ, Roth T, Blumberg A. Polymicrobial brain abscess in a patient with human inmunodeficiency virus. Clin Infect Dis 1997; 24: 449-451

7. Antony SJ, Stratton CW. Grupo Streptococcus intermedius. En Mandell GL, Douglas G, Bennet JE, eds. Enfermedades infecciosas. Principios y práctica. Buenos Aires: Ed. Médica Panamericana; 2002.p. 2648-56

8. Yamamoto M, Fukushima T, Ohshiro S, Yoshinori G, Tsugu H, Kono $\mathrm{K}$ et al. Brain abscess caused by Streptococcus intermedius: two case reports. Surg Neurol 1999; 51: 219-212

9. Shinzato T, Saito A. A mechanism of pathogenicity of "Streptococcus milleri group" in pulmonary infection: synergy with an anaerobe. J Med Microbiol 1994; 40: 118-123

10. Salavert M, Gomez L, Rodriguez-Carballeira M, Xercavins M, Freixas N, Garau J. Seven-year review of bacteremia caused by Streptococcus milleri and other viridans streptococci. Eur J Clin Microbiol Infect Dis 1996; 15: 365-71.

11. Doern GV, Ferraro MJ, Brueggemann AB, Ruoff KL. Emergence of High Rates of Antimicrobial Resistance among Viridans Group Strepto- cocci in the United States. Antimicriob. Agents Chemother 1996; 40: 891-894

12. Chun CH, Johnson JD, Hofstetter M, Raff MJ. Brain abscess. A study of 45 consecutive cases. Medicine 1986; 65: 415-431

13. Levy RM, Russell E, Yungbluth M, Hidvegi DF, Brody BA, Dal Canto MC. The efficacy of image-guided stereotactic brain biopsy in neurologically symptomatic acquired immunodeficiency syndrome patients. Neurosurgery 1992; 30: 186-190

14. Luft BJ, Remington JS. Toxoplasmic encephalitis in AIDS. CID 1992; 15: 211-222

15. Pitlik SD, Rios A, Hersh EM, Bolivar R, Mansell PWA. Polymicrobial brain abscess in a homosexual man with Kaposi's sarcoma. South Med J 1984; 77: 271-272

16. Smith NP, Nelson MR, Moore D, Gazzard BG. Cerebral abscesses in a patient with AIDS caused by methicilin-resistant Staphylococcus aureus. Int J STD AIDS 1997; 8: 459-460

17. Thurnheer R, Vernazza PL, Galeazzi RL. Recurrent brain abscesses in an HIV positive patient with hereditary hemorrhagic telangiectasia and arteriovenous malformations of the lung. Eur J Clin Microbiol Infect Dis 1996; 15: 407-410

18. Coll B, Pérez RM, Alonso C, Fernández R, Ballester M, Masana L. Afectación multiorgánica por Streptococcus constellatus en paciente VIH positivo y carga viral negativa. An Med Interna (Madrid) 2001; 18: 660-661

19. Passeron C, Peyrade F, Taillan B, Tchiknavorian X, Dujardin P. Streptococcus constellatus cerebral abscess in a patient with HIV infection. Presse Med 1997; 26: 1145

20. Holloway RG, Mushlin AI. Intracraneal mass lessions in adquired immunodeficiency syndrome: using decision analysis to determine the effectiveness of stereotactic brain biopsy. Neurology 1996; 46: 1010-1015. 